\title{
El régimen jurídico de la motivación de sentencias y actos administrativos, su relación de causalidad con la vulneración de derechos y actos de corrupción.
}

Lack of motivation for judicial decisions and administrative acts: a window open to acts of corruption

Carlos Villacreses Valencia*
Investigador Jurídico Independiente

Infomación del Artículo

Original - Ruptura, 2020

Artículo recibido / Received: 26 de agosto, 2020

Artículo aceptado / Accepted: 25 de noviembre, 2020

\section{Citación}

Villacreses, C. (2020). El régimen jurídico de la motivación de sentencias y actos administrativos, su relación de causalidad con la vulneración de derechos y actos de corrupción. Revista Ruptura de la Asociación Escuela de Derecho PUCE. Edición 2020, p (253-281).

DOI: $10.26807 /$ rr.vi02.5

Resumen: La investigación se encuentra dividida en cuatro etapas conexas, las dos primeras pretenden contextualizar al lector sobre la naturaleza jurídica de la sentencia judicial, la importancia de la motivación en la sentencia y la protección normativa que el derecho constitucional prescribe en favor de toda resolución de naturaleza

* $\quad$ Estudiante de Jurisprudencia y Finanzas de Cuarto año por la Universidad San Francisco de Quito. Diplomado Superior en Ciencias Penales y Criminología (c) por el Instituto Interamericano de Investigación y Publicaciones Jurídicas. Editor Junior de la USFQ Law Review VII Edición (2020). Actualmente es asistente legal en Responsibility Firm, ciudad de Quito. Correo electrónico: cvillacreses1@estud.usfq.edu.ec 
pública, la cual debe ser suficiente y coherentemente motivada como método de protección ante eventuales abusos de poder y casos de corrupción por parte de funcionarios públicos. La investigación aborda un estudio profundo sobre la potestad administrativa sancionadora que cubre al funcionario público e incluso la responsabilidad penal.

Una vez realizado el análisis que incluye doctrina y jurisprudencia internacional, la investigación analiza casos reales en que la falta de motivación tiene efectos sobre los derechos de los ciudadanos. En la sección tercera, la investigación revela faltas reiteradas por parte de los jueces del Tribunal Multicompetente de Pastaza, lo cual merece especial atención por parte del Consejo de la Judicatura. En la sección final, se evidencia un caso donde la ausencia de motivación en un proceso de contratación pública directa ocasionó un escándalo por supuesta corrupción.

Palabras clave: Juez; Sentencia; Destitución; Corrupción; Acto Administrativo; Contratación pública.

Abstract: The investigation is divided into four related stages, the first two are intended to contextualize the reader about the legal nature of the court ruling, the importance of the motivation in the judicial resolution and the way in which the law protects the constitutional right to receive any resolution of a public nature in a sufficiently and coherently motivated way as a method of protection against possible abuses of power and cases of corruption by public officials. The investigation deals with a deep study on the administrative sanctioning power that covers the public official and even criminal responsibility.

Once the analysis that includes international doctrine and jurisprudence has been carried out, the investigation analyzes real cases in which the lack of motivation has effects on the rights of citizens. In the third section, the investigation reveals repeated faults on the part of the judges of the Multi-competent Court of Pastaza, which deserves special attention from the Council of the Judiciary. In the final section, there is evidence of a case where the lack of motivation in a direct public procurement process caused a scandal for alleged corruption. 
Keywords: Judge; Judicial Decision; Dismissal; Corruption; Administrative Act; Public contracting.

\section{Introducción}

Esta investigación encuentra razón suficiente para considerar que la sentencia judicial y los actos administrativos inmotivados son hechos que merecen especial atención por parte de los organismos de control tanto para la protección efectiva de los derechos del particular como para identificar posibles actos de corrupción.

El orden de prelación que manejará la investigación es un análisis de la naturaleza jurídica de la sentencia judicial desde el punto de vista doctrinario, las garantías esenciales del debido proceso y la motivación como un derecho constitucional reconocido y tutelado. Posteriormente se analiza la potestad administrativa sancionadora y su diferencia con la potestad coactiva como método de sanción a la actitud negligente o dolosa del funcionario público.

Para materializar fácticamente todo lo estudiado, se analizarán casos de dictámenes judiciales objeto de recurso de casación por la Corte Nacional de Justicia debido a un vicio en la motivación, tema que resulta alarmante por la recurrente participación de los jueces que conformaron el Tribunal Multicompetente de Pastaza y por la falta de indagación de los hechos por parte del Consejo de la Judicatura. Adicionalmente, se estudiará el acto administrativo que adjudica un contrato público de manera directa en virtud del estado de emergencia que vive el país debido al COVID-19 que aparentemente maneja sobreprecios, evento que causó alarma social en la última semana del mes de marzo de 2020 y cuya consecuencia son más de una docena de casos judicializados hasta la actualidad.

Se pretende, de forma sucinta pero suficiente demostrar el nexo que existe entre el cometimiento de actos de corrupción, la vulneración de derechos y la falta de motivación en los actos y resoluciones de los poderes públicos. 


\title{
I. Sobre la naturaleza jurídica de la sentencia judicial y el acto administrativo. La implicación del deber de motivación
}

\author{
En palabras de Vescovi (2006):
}

Los hombres en sociedad tienen conflictos de intereses en virtud de que los bienes de la vida no alcanzan para las necesidades ni los deseos de todos. Surgen así las pretensiones de algunos que no son aceptados por otros sino resistidas, lo cual genera la controversia. (p.76).

La traba de la litis nace de las pretensiones particulares contrapuestas y, por ende, se requiere de un ente imparcial y ecuánime que decida, en subsunción de los hechos y la norma jurídica a quién ampara el derecho reclamado y por qué. Esta visión corresponde al sentido más tradicional de administración de justicia, aun cuando las nuevas vertientes admiten los métodos alternativos de solución de conflictos, en los cuales los particulares son investidos por las partes para actuar en el lugar del juzgador.

Las controversias, según Vescovi (2006), han de ser resueltas en restricto apego a normas jurídicas previamente sometidas al principio de publicidad. El tratadista antes referido desarrolla dentro de la teoría de los derechos "prestacionales" y "abstencionales" la hipótesis de existencia de derechos que requieren la intervención del Estado como medio de garantía, mientras que otros requieren la abstención de intromisión del Estado para ser respetados y ejercidos. Cuando se trata de administrar justicia, por regla general, es el Estado quien posee la facultad de resolver el conflicto a través de sus órganos jurisdiccionales. La Constitución de la República del Ecuador así lo prescribe en el artículo 75:

Toda persona tiene derecho al acceso gratuito a la justicia y a la tutela efectiva, imparcial y expedita de sus derechos e intereses, con sujeción a los principios de inmediación y celeridad; en ningún caso quedará en indefensión. El incumplimiento de las resoluciones judiciales será sancionado por la ley (CRE, 2008). 
La Función Judicial, en palabras de Oyarte (2019) determina que "está compuesta por órganos que ejercen la potestad pública de juzgar y hacer ejecutar lo juzgado" (p.164). El núcleo del sistema procesal consiste en una serie de actos procesales encaminados en el tiempo, dominados por el principio de preclusión procesal y amparados en normativa previa y expresa que permitan al juez dirimir la controversia y actuar conforme la pretensión de las partes, en representación de la Función Judicial y revestidos de competencia.

Sin embargo, para que la actuación judicial tenga sentido y eficacia, necesita ajustar su labor al acto que le distingue de los demás funcionarios públicos. Este acto especial se puede atribuir a un acto decisorio o sentencia. Es el juez quien, en las palabras de Devis-Echandía (2019), "dirige y decide el litigio o resuelve las peticiones que sin controversia se le presenten" (p.211). Para cumplir el mandato constitucional, el juez claramente tiene algunos poderes únicos otorgados por su jurisdicción; poder de decisión, de coerción y de ejecución. Según Devis-Echandía (2019), "la sentencia es el acto por el cual el juez cumple la obligación jurisdiccional derivada de la acción y del derecho de contradicción, de resolver sobre las pretensiones del demandante y las excepciones de mérito o fondo del demandando" (p.213).

La sentencia es el acto central de todo proceso, cada uno de los actos procesales llevados a cabo por las partes y el juez están encaminados a la resolución judicial motivada, es aquí donde se concretiza la efectividad de la norma jurídica y se materializa el derecho abstracto en una realidad plausible. Sin embargo, no podemos simplemente pensar en una sentencia como una decisión, sino en una decisión razonada. Atienza (2018), enfatiza que "La obligación de los jueces de motivar sus decisiones significa que se deben ofrecer razones suficientes en la forma adecuada para lograr la persuasión” (p.71).

Cuando Atienza (2018) discute sobre "la obligación" del juez de motivar la sentencia, se relaciona a una connotación histórica del cual se extrae el latinismo "Da mihi factum dabo tibi ius" que expresa "quien tiene la Ley, tiene el poder". En un ejercicio práctico, el particular se relaciona con el juez dándole la capacidad de examinar los hechos a expectativa de que se le otorgue o ratifique un derecho 
alegado en virtud de un análisis fáctico y normativo. ¿El juez da el derecho? La respuesta es sin duda afirmativa, el juez puede restringir, reconocer o ratificar un derecho en virtud de su potestad pública de administración de justicia materializada en la sentencia.

La evaluación del razonamiento judicial es sin duda fundamental para discutir una arista esencial del Derecho Procesal; la doble instancia o capacidad de impugnación, pues ¿cómo podría una parte apelar la decisión de un juez si no conoce su razón de decidir?, ¿cómo puede una parte sentirse igual en un proceso si no hay una razón que explique su decisión? Debido a estos cuestionamientos, el legislador lleva a un grado normativo expreso la obligación de tener una sentencia razonada en el texto Constitucional.

Las resoluciones de los poderes públicos deberán ser motivadas. No habrá motivación si en la resolución no se enuncian las normas o principios jurídicos en que se funda y no se explica la pertinencia de su aplicación a los antecedentes de hecho. Los actos administrativos, resoluciones o fallos que no se encuentren debidamente motivados se considerarán nulos. Las servidoras o servidores responsables serán sancionados (CRE, 2008, art.76 numeral 7 inciso 1).

Analizando la norma constitucional, resalta la sanción que el legislador prevé para la indebida o insuficiente motivación de un acto o resolución de poder público. La doctrina señala dos tipos de sanciones; subsanables y no subsanables, siendo estas últimas conocidas como "nulidades absolutas". La nulidad absoluta se entiende como un vicio en la actuación cuya gravedad es tal que no puede ser saneada ni siquiera por ratificación o consentimiento del sujeto a quien afecte sus derechos. Este análisis doctrinario permite dimensionar la gravedad de la falta de motivación y su doble consecuencia; la nulidad del acto y la sanción correspondiente al servidor público responsable.

En efecto, el Código Orgánico General de Procesos prescribe:

Toda sentencia y auto serán motivados, bajo pena de nulidad. No habrá tal motivación si en la resolución no se enuncian las normas o principios jurídicos en que se funda y no se explica la pertinencia de su aplicación 
a los antecedentes de hecho. Las sentencias se motivarán expresando los razonamientos fácticos y jurídicos, que conducen a la apreciación y valoración de las pruebas como a la interpretación y aplicación del derecho. La nulidad por falta de motivación única y exclusivamente podrá ser alegada como fundamento del recurso de apelación o causal del recurso de casación (COGEP, 2015, art.89).

De esta norma resalta la plena concordancia con la norma constitucional al establecer la importancia de que la decisión judicial tenga un sustento de razonamiento. La falta de motivación podrá ser alegada como fundamento del recurso de apelación o causal del recurso de casación, siendo claramente el derecho al debido proceso aquello que se pretende tutelar. Por otro lado, abordando la naturaleza jurídica del acto administrativo, la definición que otorga el artículo 98 del Código Orgánico Administrativo, se desprenden varios elementos que conforman esta manifestación de la administración pública, tales como; la existencia de una declaración unilateral, la voluntad, el ejercicio de la función administrativa y los efectos jurídicos particulares o generales.

No cabe duda la relevancia de los elementos "unilateralidad" y "voluntad". En palabras de Guechá Medina (2011), la unilateralidad implica "la sola sujeción a la legalidad para el ejercicio del acto", mientras que el elemento volitivo implica "que la administración, tenga una facultad directa de imposición del derecho frente al particular". No obstante, el autor es cauto en definir estas características del acto administrativo pues las delimita en el ámbito de la sujeción al principio de legalidad, entendiéndose de forma implícita que el acto administrativo surte sus plenos efectos siempre y cuando exista un sustento normativo.

A precisión de aquello, el artículo 100 de la norma ibidem prescribe que la motivación del acto se compone de 3 elementos; i) el señalamiento de la norma aplicable con determinación de su alcance, ii) la calificación de los hechos relevantes y iii) la explicación de la pertinencia al régimen jurídico invocado en relación a los hechos determinados. El COA, asume una postura clásica sobre la legalidad del acto, siendo en principio un ejercicio de subsunción entre la norma y los hechos. Le corresponde entonces a la administración pública 
llevar a cabo dicho ejercicio, basándose en la legitimidad que la Ley le otorga para el efecto procurando no caer en la arbitrariedad.

No obstante, resultaría ingenuo y ajeno a la realidad afirmar que la administración pública no se encuentra sujeta al fallo o incluso susceptible a la arbitrariedad. Por lo cual, la norma acompaña a medida de contrapeso esa facultad de ejercer la voluntad unilateral acompañada de la presunción de legitimidad del acto administrativo con el derecho a la debida motivación y la impugnación tanto en sede administrativa como judicial. La motivación del acto administrativo cobra especial importancia cuando existe un margen de discrecionalidad en la actuación del funcionario público. En criterio de Solanes y Gonzalez (2017):

las potestades regladas requieren necesariamente de un margen (aunque mínimo) de discrecionalidad en la aplicación de las formas, las cuestiones resolutivas y los métodos a emplearse. Pues la norma no pretende convertir a la administración en un ente mecánico sino dinámico (en medida de lo posible) (p.112).

Pretender deslindar el deber de motivación dentro del margen de discreción por más pequeño que este sea podría afectar a la legalidad de los actos, las formas y el proceso que la Ley dispone.

Precisamente, la norma cataloga a la motivación como un elemento esencial del acto administrativo incluso en su fase discrecional pues los argumentos fácticos y jurídicos permiten que el particular a quien el acto afectó su esfera de derechos pueda ejercer su derecho de impugnación de manera efectiva. Por ejemplo, si se demostrase que no existe vía idónea más directa para la protección de un derecho y se desea dejar sin efecto el acto administrativo por la vía constitucional, la Ley Orgánica de Garantías Jurisdiccionales y Control Constitucional establece en su artículo 42 como causal de improcedencia de la acción que "de los hechos no se desprenda que existe una violación de derechos constitucionales". No obstante, si la administración no expresa dentro del mismo acto cómo determinada norma y determinados hechos confluyen para dar razón al acto, el particular queda desprovisto de una herramienta fundamental para su defensa. No conocería 
el fundamento legal que da origen a la arbitrariedad y por ello sería atentatorio contra los intereses del administrado. Realizado este breve análisis, cabe proceder al estudio de las consecuencias jurídicas por la falta o indebida motivación de los actos de poder públicos.

\section{Consecuencias de la falta de motivación de los actos de poder público: la potestad administrativa sancionadora y la responsabilidad penal.}

El legislador ha buscado incorporar a la norma un elemento persuasivo a la arbitrariedad; una consecuencia derivada del incumplimiento, la cual no dista demasiado de una función punitiva y se materializa a través de la potestad administrativa sancionadora.

De acuerdo con Perdomo (1997), La potestad administrativa sancionadora se define como:

la facultad de la administración pública de imponer sanciones a través de un proceso administrativo al administrado como consecuencia de una conducta ilícita, con finalidad represora que tengan como fin corregir la actuación desviada del funcionario de manera proporcional al daño causado (p. 58).

El Código Orgánico Administrativo (COA), maneja con especial cautela los procesos de sanción. Estableciendo para ello algunas reglas, entre ellas, que el funcionario conozca de manera premeditada las causales que provocarían la eventual sanción y que, en caso de establecerse la sanción, esta sea comunicada de forma oportuna para garantizar el pleno goce de su derecho a la contradicción. Demás reglas están contenidas en el artículo 248 del COA.

Los procesos sancionatorios inician en virtud del principio de unilateralidad, es decir, por simple voluntad sustentada de la entidad pública legalmente habilitada para sancionar. La sustanciación de dicho proceso está reglada en el artículo 250 del COA y subsiguientes. Realizando una breve síntesis, el procedimiento inicia de oficio o a petición de parte mediante acto administrativo que contenga la identificación 
de la o las personas presuntamente responsables, la relación con los hechos, el detalle de los documentos necesarios para esclarecer los hechos y la determinación del órgano competente para resolver el caso. Posteriormente, se procede a la notificación del oficio a los interesados, se da un término de 10 días para la contestación y consecuente oposición del particular, análisis de la prueba y dictamen.

Es menester puntualizar que, la sanción cubre a todos los funcionarios públicos en razón de sus obligaciones implícitas y explícitas. Por ejemplo, no es necesario que la norma afirme explícitamente el principio de "alterum non laedere" o "prohibición de dañar injustificadamente", sino que se entiende implícita por los principios que envuelven al funcionario público contenidos en el COA y la Constitución

Respecto al análisis doctrinario sobre la importancia de la motivación en las resoluciones judiciales, Oyarte (2014) opina que:

La motivación, como lo ha indicado nuestra jurisprudencia constitucional, no se cumple de un modo meramente formal o con la simple cita de preceptos jurídicos o de tratadistas, ni con la reproducción total o parcial de los argumentos esgrimidos por las partes dentro de un fallo. Todo lo contrario, la motivación constituye un juicio lógico que enlaza los hechos y el derecho para obtener como conclusión una consecuencia jurídica (p.117).

Las normas reglamentarias y sancionatorias de los funcionarios judiciales constan en el COFJ con un diferente estándar al de otros funcionarios públicos. Sobre este aspecto, la Corte Constitucional de Colombia interpreta que:

La responsabilidad disciplinaria de jueces y magistrados no puede abarcar el campo funcional, esto es el que atañe a la autonomía en la interpretación y aplicación del derecho según sus competencias. Por consiguiente, el hecho de proferir una sentencia judicial en cumplimiento de la función de administrar justicia no da lugar a acusación ni a proceso disciplinario alguno. Si se comprueba la comisión de un delito al ejercer tales atribuciones, la competente para imponer la sanción es la justicia penal en los términos constitucionales y no la autoridad disciplinaria. (Corte Constitucional de Colombia, No. C-417-1993). 
En Ecuador, las sanciones administrativas no son excluyentes de la responsabilidad penal. El legislador ha optado por categorizar la gravedad de la falta entre leves, graves y gravísimas (COFJ, artículos 107-109). Esta gradualidad existe en virtud del principio de proporcionalidad, atendiendo a la frecuencia y la concurrencia de una o varias faltas. La sanción disciplinaria persigue una finalidad distinta a la responsabilidad penal, pues la primera se agota con lo dispuesto en el artículo 105 del COFJ, siendo la destitución la consecuencia más severa prevista en el ámbito administrativo. Por otro lado, la responsabilidad penal considera el elemento subjetivo de la conducta, así mismo la necesidad de reparación integral por los actos u omisiones causados. En el caso de la falta o incorrecta motivación de las resoluciones judiciales, la Ley es clara al contenerla dentro de las faltas graves. Causales que se contienen dentro del Código Orgánico de la Función Judicial:

No haber fundamentado debidamente sus actos administrativos, resoluciones o sentencias, según corresponda, o en general en la substanciación y resolución de las causas, haber violado los derechos y garantías constitucionales en la forma prevista en los artículos 75, 76 y 77 de la Constitución de la República (COFJ, 2009, artículo 108).

La falta de motivación ha sido considerada como una circunstancia constitutiva de infracción incluso por la jurisprudencia internacional. En el caso "Zegarra Marín vs Perú" (CIDH, 2017) La Corte Interamericana de Derechos humanos reconoció la importancia de tener una sentencia motivada. En el caso, se determinó que el Estado violó la presunción de inocencia y no se garantizó la motivación del fallo.

Es precisamente el análisis intelectual llevado a cabo por el juez, materializado en su motivación lo que debe constituir el factor determinante que fracture el principio de Presunción de Inocencia. El análisis debe basarse en los principios procesales comunes a la legislación peruana, entre ellos la libertad probatoria, pero sobre todo la conexión lógica entre la norma aplicable al caso y las pruebas aportadas al proceso que acrediten los hechos facticos pertinentes" (Corte IDH, 2017). 
La sentencia condenatoria emitida en el proceso penal en contra del señor Zegarra Marín carece de efectos jurídicos en lo que respecta a la víctima del caso, y por lo tanto, que el Estado debe adoptar todas las medidas necesarias para dejar sin efecto las consecuencias que de ella derivan, así como los antecedentes judiciales o administrativos, penales o policiales que existieran en su contra a raíz de dicho proceso; como medida de satisfacción (Corte IDH, 2017, Caso Zegarra Marín vs. Perú). En la responsabilidad internacional, una sentencia que no haya cumplido con el estándar mínimo de la debida motivación adolece de un vicio de nulidad insubsanable, consecuentemente al derecho de reparación del ciudadano afectado por una actuación judicial errada. Esto concuerda con la Convención Americana sobre Derechos Humanos, en el artículo 8 ya menciona un pilar muy importante para esta discusión:

Toda persona tiene derecho a ser oída, con las debidas garantías y dentro de un plazo razonable, por un juez o tribunal competente, independiente e imparcial, establecido con anterioridad por la ley, en la sustanciación de cualquier acusación penal formulada contra ella, o para la determinación de sus derechos y obligaciones de orden civil, laboral, fiscal o de cualquier otro carácter (OEA, CADH, art.8)

Con "debidas garantías" se entiende, según el Cuadernillo de Jurisprudencia de la Corte interamericana de DD. HH. Número 12 la garantía al "debido proceso".

Igualmente, las garantías generales contenidas en el artículo 8.1 de la Convención Americana de Derechos Humanos (CADH), como "el derecho a ser oído dentro de juicio, a ser juzgado por un tribunal independiente, imparcial y competente, así como a obtener una resolución motivada." (Corte IDH, 2016). Los párrafos precedentes son clara muestra de la concordancia del Derecho interno ecuatoriano con las normas y jurisprudencia de carácter internacional que concuerdan en el deber judicial de motivación de la sentencia como un pilar esencial del debido proceso, cuya inobservancia constituye infracción grave que puede claramente llevar a una destitución del cargo. 
Una vez abordada la problemática desde la normativa internacional y explicado el carácter sancionador de la administración pública, es menester realizar una pregunta que sostenga una realidad menos dogmática y más práctica. ¿Por qué un juez conociendo de todo este antecedente no motivaría su sentencia?

Claramente no existe una respuesta académica a esta pregunta sino un abanico multicausal de posibilidades. En este punto es determinante la labor investigativa de los organismos de control sobre la posible implicación del funcionario en delitos contra la administración pública; es decir, eventuales casos de corrupción (Corte IDH, 2017).

En un país donde existe escasa credibilidad del sistema de administración de justicia, no es descabellado que exista una natural desconfianza sobre la ecuanimidad del juez al momento de decidir. Ya sea por presiones políticas o por dádivas económicas, un sistema de justicia quebrantado tiene serios riesgos en incurrir en ilícitos penales. En esencia, el temor del particular es que el juez actúe de forma apartada a la Ley y en beneficio de una de las partes a cambio de un enriquecimiento patrimonial ilícito. La gravedad del asunto radica en que el poder judicial se vería condicionado al poder económico, dejando indefensas a las partes vulnerables dentro de la relación jurídico-procesal y convirtiendo el principio de la igualdad ante la Ley en una completa ficción. La forma más sencilla para lograrlo es disfrazar la legalidad de una sentencia judicial con una motivación aparentemente suficiente, pero que en el fondo no se ajusta a los hechos del caso ni a la norma jurídica pertinente. Cuando el funcionario recibe dádivas o se enriquece a costa de su puesto concurren tipos penales como el del artículo 280 del COIP:

Cohecho.- Las o los servidores públicos y las personas que actúen en virtud de una potestad estatal en alguna de las instituciones del Estado, enumeradas en la Constitución de la República, que reciban o acepten, por sí o por interpuesta persona, beneficio económico indebido o de otra clase para sí o un tercero, sea para hacer, omitir, agilitar, retardar o condicionar cuestiones relativas a sus funciones, serán sancionados con pena privativa de libertad de uno a tres años [...] (COIP, 2014, articulo 280). 
Resulta complejo creer, en medida de la practicidad, que el funcionario se aleje de sus obligaciones incluso sabiendo las sanciones previstas para ello en el Código Orgánico de la Función Judicial sin recibir algún tipo de beneficio patrimonial. Muestra de ello es el proceso penal número 17721-2019-00013, en el cual el Ex Juez de la Provincia de Pastaza, Aurelio Quito fue sentenciado por cohecho y condenado a cumplir pena privativa de libertad más medidas de reparación integral (Letamendi, 2020). El Ex Juez habría ofrecido a otro magistrado beneficio económico para ratificar una sentencia dictada por concepto de acción de protección. El juez denunciante, Dr. John Álava manifestó en audiencia que se pretendió de él una actuación apartada del derecho, maleando los hechos del caso e interpretando parcial e inconsistentemente la prueba, por lo cual la motivación de su sentencia sería favorable a los intereses de la parte demandada. En otros casos, que no se explicarán a profundidad pues cuestiones de síntesis, otros tipos penales han sido configurados por actuaciones dolosas de los jueces, tal es el caso del ex juez provincial de Pichincha Édgar Flores Gonza por el presunto delito de tráfico de influencias (Galarza, 2020).

\section{La falta de motivación en las sentencias y su presencia en la administración de justicia en el Ecuador. ¿Es el Tribunal de Pastaza merecedor de una sanción administrativa?}

Esta labor investigativa determinó una serie de acontecimientos que merecen especial atención por parte del Consejo de la Judicatura debido a la recurrente actuación equivoca de los jueces que conforman el Tribunal Multicompetente de Pastaza en los diversos procesos puestos a su conocimiento desde el año 2013. Para efectos de este ensayo, constituye una muestra ejemplificativa de cómo la falta de motivación de parte de la administración de justicia puede vulnerar derechos y cómo la problemática no es ajena a la realidad jurídica del país. En todos ellos, la motivación de la sentencia ha excedido la Ley, ha sido insuficiente o incorrecta, lo cual resulta tremendamente perjudicial para las partes involucradas. 
Se analizará las siguientes causas que son de acceso y conocimiento público:

\subsection{Causa No. 16281-2016-0013}

La Sala Especializada de los Penal, Penal Militar, Penal Policial y Tránsito de la Corte Nacional de Justicia, casa la sentencia emitida en 2016 el 20 de febrero de 2017 por el Tribunal Multicompetente de la Corte Provincial de Pastaza integrado por los Jueces Juan Sailema Armijos, Enrique Bolívar Torres y Carlos Medina Riofrío debido a la ausencia de un sustento motivacional adecuado a los hechos. En el caso, el Tribunal Provincial llegó a la conclusión de la culpabilidad del procesado, Sr. Marco Vinicio Barrionuevo sin que se haya probado en juicio la forma en que se materializó el supuesto delito: modo, tiempo, lugar ni monto del perjuicio al Estado por el delito de Peculado. La CNJ recalca que, si bien la norma jurídica ampara la sana crítica como método de valoración de la prueba, esta no puede ser incoherente ni arbitraria. En palabras de la Corte Nacional, la sentencia casada:

evidencia una falta de coherencia en la construcción de la argumentación, que transgrede el principio de la lógica. Lo expuesto, repercute en la parte resolutoria del fallo por cuanto los Jueces de segunda instancia ratifican la inocencia del procesado (...) sin efectuar un análisis coherente (...) (CNJ, No. 16281-2016-0013).

\subsection{Causa No. 256-2013-SF}

En este proceso, la Sala especializada de lo Penal de la Corte Nacional de Justicia determina que el Tribunal ad quem de Pastaza, emitió un fallo declarando la inocencia del procesado revocando lo decidido por el Tribunal Penal. Dado que la decisión judicial modifica la esfera jurídica del individuo respecto de sus derechos, aplica lo dispuesto en el artículo 76.7.1 de la Constitución. Sin embargo, la Corte Provincial de Pastaza vulneró, en palabras de la Corte de Casación: "las garantías más básicas del debido proceso. Aplicó normas penales 
imprecisas, incongruentes e inadecuadas a los hechos fácticos, por lo cual se procedió a anularla por indebida motivación" (CNJ, No. 2562013-SF). Los Jueces que actuaron en esta causa fueron la Dra. Tania Masson, Dr. Bolívar Torres y el Dr. Oswaldo Vimos (voto salvado).

\subsection{Causa No. 234-2013}

En esta causa, el Tribunal de la Corte Provincial de Pastaza integrado por el Dr. Bolívar Torres, Dra. Tania Masson y el Dr. Frowen Alcívar, declara por unanimidad la culpabilidad del ciudadano Eddy Rafael Barreno Rojas como autor del delito de uso doloso de documento público falso. La sentencia referida fue objeto de recurso extraordinario de Casación. La CNJ casa la sentencia en su totalidad debido a un error en la aplicación de la norma jurídica. La Corte precisa que:

se evidencia el yerro en que ha incurrido la Sala Única de la Corte Provincial de Pastaza al tomar en consideración que el recurrente no es una persona peligrosa, de haber reparado el daño con la licencia profesional, expresiones y consideraciones personalísimas del órgano jurisdiccional que no se adecuan a las circunstancias atenuantes previstas en el ordenamiento jurídico penal ecuatoriano (...)" (CNJ, No. 234-2013).

La precisión antes citada se encuentra a fojas ciento treinta y cuatro del expediente pertinente. Es menester resaltar que, el díctum de la sentencia dispone se oficie al Consejo de la Judicatura un proceso de investigación acerca de la actuación de los jueces del Tribunal ad quem.

\subsection{Causa No. 17721-2016-1704}

La Corte Nacional de Justicia (2016), anula nuevamente una sentencia emitida por la Corte Provincial de Pastaza debido a la falta de motivación. En el caso el tribunal de alzada excluye sin sustento apropiado el testimonio de Galo Altamirano bajo la denominación de "amigo íntimo" de la persona procesada acudiendo a la semántica y a la norma Procesal Civil, que es ajena a la norma propiamente aplicable del Código 
de Procedimiento Penal que, en su artículo 84 prescribe el principio de Libertad Probatoria. (CNJ, No. 17721-2016-1704).

Por lo expuesto, la CNJ resuelve casar la sentencia del tribunal de segunda instancia a costas de los jueces que lo componen, en el presente caso: Dr. Bolívar Torres, Dr. Carlos Medina y Dr. Juan Sailema.

En los casos antes expuesto confluyen dos alarmantes factores: primero, que el error que provoca la nulidad de la sentencia tiene que ver con yerros en la motivación y segundo, la recurrente actuación de los jueces Torres, Medina, Sailema y Masson. Si bien el Consejo de la Judicatura tiene entera potestad discrecional sobre el procedimiento de sanción, se cree menester la apertura de un profundo proceso de investigación afín de precautelar un sistema de administración de justicia responsable. Dado que el efecto de la casación es retrotraer el proceso al momento en que se incurrió en la causal alegada, es tremendamente gravoso para las partes, para la credibilidad del sistema de justicia y la celeridad del proceso que esto ocurra por inadecuada labor judicial. El Iura novit curia no se evidencia en la investidura sino en la experticia de la labor judicial materializada a través de una motivación jurídicamente conexa entre los hechos probados y la norma aplicable al caso.

Ante la actuación del tribunal de Pastaza, el Consejo de la Judicatura debería determinar si concurren los elementos configurativos de sanción contenidos en los artículos 108, 110 y 112 del COFJ. A criterio del autor, quedan claramente alineados los elementos del numeral cuarto del artículo 110 sobre la recurrencia de las infracciones. Por otro lado, el inciso final del artículo 108 vuelve menester analizar si existe reiteración en las faltas por tres ocasiones en un periodo de un año. En este sentido, la norma es oscura respecto a la necesidad de que la infracción deba ser declarada varias veces vía sumario administrativo para considerarse una reiteración, o si basta condensar en un solo proceso sancionatorio la evidencia de faltas reiteradas. En nuestro criterio, sería improcedente ignorar el principio de celeridad como una columna rectora en los procedimientos administrativos, por lo cual, la acumulación debidamente justificada de infracciones en el mismo proceso sancionatorio debería ser suficiente para determinar que una conducta impropia del funcionario 
merece ser catalogada como recurrente y merecedora de una sanción más fuerte. Todo lo antedicho queda expuesto sin perjuicio de que la autoridad administrativa pudiere llegar a considerar una actuación atentatoria recurrente como contenida dentro del artículo 109 del COFJ respecto a la manifiesta negligencia, el dolo o el error inexcusable. Es claro que la falta de motivación atenta contra los principios rectores del debido proceso contenidos esencialmente en los artículos 76 y 77 de la Constitución, por cuanto la actuación que los ignora podría incluso ser manifiestamente negligente o dolosa.

A propósito del procedimiento sumario administrativo, la Corte Constitucional (2020), en la sentencia 3-19-CN/20 decidió que "previo al eventual inicio del sumario administrativo en el Consejo de la Judicatura contra un juez, fiscal o defensor público, se realice siempre una declaración jurisdiccional debidamente motivada de la existencia de dolo, manifiesta negligencia o error inexcusable”. Decisión que fue altamente criticada pues limita la capacidad del Consejo de la Judicatura para actuar de forma oficiosa en los procesos sancionatorios y crea un requisito de prejudicialidad. El proceso sumario administrativo requerirá una declaración jurisdiccional conocida por el juez superior, lo cual pretende proteger el derecho a la independencia judicial. No obstante, crea una traba al control de las actuaciones irregulares de los jueces por cuanto la carrera judicial es extensa y se ignora un elemento extrajurídico: la humanidad de los jueces y la amistad que existe entre ellos. Confiar el control de un juez en manos de otro juez con quien comparte carrera, colegas e incluso aspiraciones es sumamente peligroso para la administración de justicia.

Ante todo lo expuesto sobre el Tribunal Multicompetente de Pastaza, queda claro que la realidad jurídica del país aún conserva el problema latente de la indebida o insuficiente motivación en las decisiones judiciales. No existe un mecanismo eficaz para proteger los derechos de los particulares ante las actuaciones negligentes de los jueces pues el procedimiento sancionatorio ahora requiere un elemento de prejudicialidad que retarda y vuelve inverosímil la materialización de una sanción. La consecuencia de ello recae sobre la credibilidad del sistema de justicia, y sobre el menoscabo del debido proceso, institución que un país caótico como el nuestro aún está en miras de construirse. 


\section{La implicación de la falta de motivación en la lesión de los intereses generales del Estado: los procesos de contratación pública inmotivados y los actos de corrupción.}

Los procesos de contratación pública no escapan al deber de motivación, por cuanto la adjudicación de una obra pública se emite vía acto administrativo. De acuerdo con el artículo 89 del Código Orgánico Administrativo (2017), el acto administrativo es una forma en la cual se expresa la voluntad de la administración pública, entendida como una "declaración unilateral de voluntad, efectuada en ejercicio de la función administrativa que produce efectos jurídicos individuales o generales, siempre que se agote con su cumplimiento y de forma directa [...]". La adjudicación de una obra, bien o servicio por parte de una entidad pública a un contratista privado es un acto administrativo que no escapa de dos facetas a menudo contrapuestas: 1) La presunción de legitimidad y validez 2) la nulidad constitucional por falta de motivación (Pérez, 2009).

La contraposición existe dado que, incluso aquellos actos cuya motivación sea manifiestamente arbitraria se presumen válidos y requiere ser declarados nulos después de un proceso contencioso administrativo, ya que el ordenamiento jurídico no prevé la nulidad de ipso iure.

Respecto a las compras públicas, la Ley Orgánica del Sistema Nacional de Contratación Pública (2008), en adelante LOSNCP, prevé varios tipos de modelos precontractuales sustentados en el principio de legalidad. Su diferencia radical con la contratación privada es el interés colectivo que se esconde detrás y la naturaleza de los fondos públicos. Muestra de esto es lo prescrito por la norma constitucional; "Las compras públicas cumplirán con criterios de eficiencia, transparencia, calidad, responsabilidad ambiental y social" (CRE, 2008, artículo 288).

La doctrina define la eficiencia desde la lógica jurídico-económica como "la capacidad de satisfacer una necesidad existente y prioritaria utilizando la menor cantidad de recursos económicos y temporales posibles" (Gómez, 2019), la igualdad es entendida como "el 
similar punto de partida entre los oferentes respecto a su poder de negociación y participación" (Gómez, 2019) y la transparencia es "la característica esencial de un proceso de compra pública en el cual el privado obtiene su calidad de contratista de forma legítima y meritoria” (Morales, 2016, p.26). El legislador entendió que la forma de evitar la natural tendencia al enriquecimiento del funcionario por medio de dádivas era limitando su potestad discrecional, respaldando su accionar normativamente, esto es expreso dentro del artículo 9 numeral tercero de la LOSNCP que plantea como uno de sus objetivos "evitar la discrecionalidad en la contratación pública". El constituyente plasmó este objetivo en la unificación del proceso de compras públicas a través del Servicio Nacional de Contratación Pública (SERCOP) evitando que prosiguiese la antigua costumbre de permitir a cada institución que se declare independiente en sus reglas de contratación.

Las reglas que anteceden un proceso precontractual se contienen en los artículos 23 a 26 de la LOSNCP, siendo el orden menester un Plan Anual de Contratación, estudios (a cargo de la misma entidad o de un consultor) y finalmente la estimación de un presupuesto referencial del costo de la obra. El presupuesto referencial se contiene en los pliegos (modelos precontractuales) que ofrecen al contratista información sobre aquellos que se pretende contratar y bajo qué procedimiento. La Ley prevé un "mejor costo" en su artículo 6 numerales 17 a 19, criterios ineludibles para declarar el adjudicatario. El breve recuento realizado tiene como objeto demostrar cómo la Ley intenta limitar al máximo la potestad discrecional al momento de contratar, desde la inversión en estudios que brinden un presupuesto referencial hasta el diseño de modelos precontractuales que varíen según el monto de la contratación y según el tipo de bien, obra o servicio (normalizado o no normalizado) que se pretenda adquirir. Sin embargo, hay varios vacíos en los cuales la norma permite la contratación directa, volviéndose la motivación absolutamente necesaria para evitar actuaciones negligentes o eventuales casos de corrupción.

El artículo 57 de la LOSNCP prevé uno de los casos más delicados de la actuación administrativa; la contratación directa en situaciones de emergencia. La norma jurídica no excluye la necesidad de 
emitir "resolución motivada que declare la emergencia para justificar la contratación”. En la práctica, pese a que la misma Ley define una situación de emergencia en su artículo sexto numeral 31, no deja de ser peligroso la ausencia de un proceso de adjudicación por mérito o por mejor costo. En la legislación ecuatoriana, la máxima autoridad de la entidad puede contratar directamente si en base a su criterio se cumple alguno de los supuestos contenidos en el numeral 31 del artículo 6 de la Ley. La norma prescribe "una situación de emergencia es concreta, inmediata, imprevista, probada y objetiva".

Ocurrida la pandemia mundial por COVID 19, Ecuador ha realizado numerosas compras con modalidad directa, la pregunta menester es: una serie de contagios que se expandieron desde el mes de octubre de 2019 y cuya llegada a Ecuador y demás territorios de la región era prevista, ¿puede ser considerada susceptible de contratación directa? Si se analiza el caso de Colombia el sistema de compras públicas de material necesario para afrontar la crisis no escapa de un concurso público y una modalidad precontractual (Pérez Becerra, 2020). Por tanto, es de imperiosa necesidad analizar cuál fue el sustento de la resolución emitida por la autoridad de Salud Pública que declaró la emergencia en territorio ecuatoriano. Para desmentir la imprevisibilidad de la urgencia en el Sistema, bastan las declaraciones que constan en el Diario El Telégrafo (2020) donde la ex ministra de Salud Pública, Catalina Andramuño afirmó que "es una situación para la cual nos preparamos desde diciembre pasado y se veía venir". A efecto de la emergencia sanitaria, el país inició numerosos procesos de contratación pública que no escapan a irregularidades.

Uno entre tantos casos irregulares en procesos de contratación salió a la luz el 22 de marzo de 2020. El Instituto Ecuatoriano de Seguridad Social, adjudicó el contrato de compra de "Dispositivos y/o insumos médicos para solventar la emergencia declarada por el COVID 19" a la empresa ALMANTOP S.A. tal como consta en el proceso con código IESS-DG-AL-2020-03200001. La motivación que acompaña al proceso de contratación es manifiestamente insuficiente: "se ha verificado el precio más conveniente para los intereses del IESS, y que representan el mayor ahorro y el cumplimiento de las especificaciones técnicas requeridas (...)" (Instituto 
Ecuatoriano de Seguridad Social, 2020). A propósito de la declaratoria de emergencia, el SERCOP publicó un boletín en su página oficial que reveló que la institución "viene realizando una supervisión estricta y permanente al $100 \%$ de los procedimientos de contratación pública, que se ejecuten bajo la modalidad de emergencia, con el objetivo de salvaguardar el buen uso de los recursos públicos”.

Dicho boletín afirma que "con el objetivo de transparentar la información, el SERCOP puso a disposición en su página web www.sercop.gob.ec, un micrositio donde se alojan todas las Resoluciones que inician los procedimientos de contratación pública por emergencia”. Revisando minuciosamente dicho espacio, notamos que a ningún momento se encuentra a libre escrutinio público las ofertas presentadas por parte de posibles adjudicatarios y menos aún la motivación que, basándose en un criterio técnico y de estándar internacional verifique que la compra se sujeta estrictamente al mejor costo señalado en el artículo 6 de la LOSNP.

Días más tarde, una denuncia ciudadana respecto de este proceso de contratación, replica que las Mascarillas N95 cuyo precio referencial unitario en el Portal Compras Públicas es de USD \$12.00, en realidad tienen un precio en el mercado que ronda los $\$ 3.95$ (al mes de marzo de 2020, pues la oferta al mes de julio abarató los precios). En reacción al escándalo realizado por entes del sector privado, la autoridad administrativa superior manifestó que "no existe irregularidad pues se ha suspendido la adjudicación del contrato" (Diario el Comercio, 28/03/2020). Sin embargo, el Portal COMPRAS PÚBLICAS refleja claramente como adjudicatario a ALMANTOP S.A.

A menester de este trabajo investigativo, es de recalcar que la norma permite la contratación directa en casos de emergencia, por tanto, en el hipotético que se demostrase que la emergencia no fue previsible, podría afirmarse que el IESS actuó con respaldo normativo respecto al procedimiento. Sin embargo, eso no excusa al ente de motivar con sustentos técnicos la adjudicación de un contrato cuyo monto total es de USD $\$ 10,017,754.60$ a determinado contratista. Dichos procesos en su integralidad deberían estar sujetos al principio de publicidad según señala la LOTAIP. 
A propósito del caso, la problemática ha llegado a manos de la Contraloría General del Estado, que anunció un proceso de auditoría respecto a los procedimientos precontractuales que se realicen en virtud del estado de emergencia sanitaria (Diario El Comercio, 2020). Dado que el asunto en cuestión saltó a la opinión pública pocas semanas antes a la entrega de este trabajo, esta investigación no puede adelantarse al pronunciamiento del organismo de control. Sin embargo, cabe puntualizar que las consecuencias derivadas de las actuaciones de los funcionarios públicos pueden ser:

- Responsabilidad administrativa culposa: según prescribe el artículo 45 de la Ley Orgánica de la Contraloría General del Estado (2002). En síntesis, incurren en estas faltas los funcionarios que, por falta a la debida diligencia hubieren actuado equivocadamente, pero sin causar perjuicio económico.

- Responsabilidad civil culposa: cuando el funcionario actúe en virtud de lo prescrito en el artículo 52 de la LOCGE, causando un perjuicio económico para la entidad pública.

- Responsabilidad penal: a propósito de esto, la Contraloría General del Estado se encuentra facultada para emitir un IRP (Informe sobre Indicios de Responsabilidad Penal) y remitirlos a la Fiscalía General del Estado, ente que debe iniciar de oficio una investigación ${ }^{1}$.

Visto que a la fecha de publicación del presente ensayo los hechos irregulares precedentes han sido judicializados, cabe opinar sobre ellos recalcando que el principio de presunción de inocencia acompaña a los imputados durante el proceso penal y se rompe únicamente ante

1 Cabe puntualizar que, desde Julio de 2019, un IRP ya no es un requisito de procedibilidad para iniciar un proceso penal contra un funcionario público por los delitos de Peculado y Enriquecimiento Ilícito. Antiguamente, el artículo 583 del COIP inciso tercero establecía dicho requisito. Cosa que fue declarada inconstitucional por intervenir en las atribuciones constitucionales de la Fiscalía (Corte Constitucional del Ecuador, 2019). 
la sentencia condenatoria ejecutoriada. Por lo cual, muy aparte de determinar la culpabilidad de los involucrados si es pertinente concluir en que el factor origen de las irregularidades es la falta de motivación suficiente al momento de contratar. La contratación arbitraria en favor de determinados proveedores del Estado es el problema medular, que se asienta en la obtención de beneficios ilícitos para el funcionario público. A efectos de ello, se presume existe aquello que la Convención Interamericana contra la Corrupción describe en su artículo quinto:

El ofrecimiento o el otorgamiento, directa o indirectamente, a un funcionario público o a una persona que ejerza funciones públicas, de cualquier objeto de valor pecuniario u otros beneficios como dádivas, favores, promesas o ventajas para ese funcionario público o para otra persona o entidad a cambio de la realización u omisión de cualquier acto en el ejercicio de sus funciones públicas (Organización de Estados Americanos, 1978).

En resumen, se ignoraron los parámetros y estándares técnicos que la LOSNCP pretendía para los concursos públicos y la contratación directa. Evidencia de aquello es la abismal diferencia entre los precios comerciales de los insumos médicos contratados con los precios efectivamente pagados, ante lo cual la administración pública no supo justificar por qué se apartó del parámetro de mejor costo contenido en el artículo 6 de la Ley ibidem. Por cuanto los hechos de la contratación no fueron enunciados con claridad y no existe congruencia con la norma aplicable para el caso, deviene en una decisión inmotivada cuyo móvil se presume incluso menester de investigación en la vía penal.

\section{Conclusiones}

El juez, está investido de poderes especiales de decisión, coerción y ejecución. La sentencia, es el acto solemne que faculta al juez a reconocer en favor de uno de los protagonistas de la traba de litis un derecho, recortar la esfera de la libertad del sujeto e incluso permite que ciertos derechos constitucionales puedan ser limitados. La Función Judicial encuentra su núcleo en los administradores de justicia, éstos a su vez en la sentencia, y la sentencia en la debida motivación. 
Vista la diferencia entre la carga y la obligación, la motivación de la sentencia es un elemento esencial de dicho acto procesal sin el cual carece de legitimidad y eficacia. La motivación tanto de sentencias como actos administrativos se componen de tres elementos sustanciales: i) la norma, ii) los hechos, iii) el razonamiento lógico del juez por el cual abstrae y complementa los dos elementos anteriores. Tal es su importancia que la norma constitucional, el Código Orgánico Administrativo y el Código Orgánico de la Función Judicial sancionan la omisión de dicha obligación.

Los actos administrativos son una manifestación de la voluntad unilateral de la administración pública cuyo efecto modifica la esfera de derechos del particular. El legislador ha delimitado dicha potestad sujetándolo a tres elementos: el principio de legalidad, el derecho a la impugnación y la debida motivación. Como resulta obvio, la administración pública se encuentra sujeta al fallo y sus funcionarios son susceptibles de quebrantar la norma ya sea por dolo o negligencia.

El legislador ha pretendido incorporar un elemento disuasivo a la falta de motivación de los actos administrativos y las sentencias a través de la potestad administrativa sancionadora que no exime al funcionario de responsabilidad penal. El funcionario judicial, tiene previsto como sanción grave el no motivar debidamente las resoluciones a su cargo. En este punto, la investigación concluye en que existe un evidente nexo causal entre las actuaciones arbitrarias de los servidores públicos y los casos de corrupción que afectan la realidad nacional y la credibilidad de todo el sector público. La corrupción galopante tiene como origen la falta de control de las actuaciones de los funcionarios públicos, siendo evidente que existe una sospecha permanente por el funcionario y su ecuanimidad.

Los actos arbitrarios, la ausencia o indebida motivación de los actos de poder públicos son una realidad presente en el país. Muestra de ello son las actuaciones reiteradas el tribunal multicompetente de Pastaza, los procesos de adjudicación de obras públicas inmotivados que derivan en procesos penales e incluso la historia reciente, a través de casos como los de los ex jueces; Aurelio Quito y Edgar Flores Gonza, procesados por cohecho y tráfico de Influencias respectivamente. 
La herramienta directa del ciudadano para luchar contra la arbitrariedad es la denuncia. No obstante, en un sistema ineficiente y demoroso, difícilmente se podrá reivindicar los derechos afectados sin requerir al ciudadano que se involucre en una tramitología interminable. Este ensayo concluye planteando un punto de discusión profunda, en el cual las autoridades de control no pueden tomar los actos inmotivados como meros acontecimientos negligentes. En muchas ocasiones, los funcionarios públicos se ven inmiscuidos en actos deshonrosos para la administración pública en miras de su propio beneficio patrimonial. Hechos que quedan en la absoluta impunidad si no existe un mecanismo pleno de investigación y sanción al funcionario que decida en desapego a la Ley o ignorando su obligación a la debida motivación. El acto más lesivo de la corrupción es el costo de oportunidad, de lo que pudimos haber sido y no somos. Por aquellas normas jurídicas que requieren urgentemente ser legisladas en beneficio del progreso, pero que son postergadas en un vaivén de interminables juicios políticos, escándalos y sainetes que mantienen al legislador ocupado mientras se aproximan las elecciones y la crisis se agudiza.

\section{Referencias Bibliográficas}

Atienza, Manuel. "La Evaluación Del Razonamiento Judicial". Curso De Argumentación Jurídica, Editorial Trotta, 2018, pp. 549-549.

Becerra, R. P. (02 de Marzo de 2020). Así será la contratación pública tras declaratoria de emergencia por el coronavirus. La FM Colombia.

Cabanellas, G. (s.f.). Enciclopedia Jurídica. Obtenido de http://www.enciclopedia-juridica.com/d/potestad-sancionadora/potestad- sancionadora.htm

Desconocido. (04 de Julio de 2019). Fiscalía ya no requiere informe previo de Contraloría para investigar peculado. El Universo.

Desconocido. (17 de Febrero de 2020). Ecuador está preparado para eventual ingreso del coronavirus: ministra. El Telégrafo. 
Galarza, V. (17 de Agosto de 2020). Exjuez de Pichincha enfrenta audiencia por tráfico de influencias. Pichincha Comunicaciones.

Guechá Medina, C. (2011). Los atributos de los actos administrativos unilaterales son aplicables a los contactos administrativos. Universidad Santo Tomás.

Imbaquingo, J. (28 de 03 de 2020). Tras Contratación de USD 12 por mascarilla, Contraloría hará auditoría. El Comercio.

Letamendi, X. (04 de Febrero de 2020). Juez Aurelio Quito condenado a un año de prisión. Primicias.

Martinez-Morales, R. (2016). Derecho Administrativo. Bogotá.

Oyarte, R. (2009). Debido Proceso. Quito: Centro de Estudios y Publicaciones.

Oyarte, R. "Capítulo Décimo Séptimo. Los Órganos Jurisdiccionales.” Derecho Constitucional, Corporación De Estudios y Publicaciones, 2019, p. 943

Perdomo, J. V., \& Betancur, C. M. M. (1997). Derecho administrativo. Temis.

Pérez-Camacho, E. (2012). Manual de Derecho Administrativo. Quito: Corporación de Estudios y Publicaciones.

Rivera, M. G. (2015). Temas de Derecho Administrativo. Madrid: Trotta.

Sercop. Boletín por Estado de Emergencia. Obtenido de: https://portal. comprasublicas.gob.ec/sercop-regula-y-controla-las-contrataciones-por-emergencia/

Solanes, J. González M. Independencia Judicial y Estatuto de los Jueces. Temis.

Velez, R. (28 de Marzo de 2020). IESS suspende órdenes de compra de mascarillas N95 para emergencia sanitaria por coronavirus en Ecuador. El Comercio. 
Vazquez-Portomeñe, F., Los delitos contra la Administración Pública. Teoría general, (Santiago de Compostela: Instituto Nacional de Administración Pública y Universidad de Santiago de Compostela 2003), pág. 83

Vescoví, E. “Teoría General del Proceso.”, TEMIS S.A, 2006, p. 167.

\section{Normativa}

Código Orgánico General de Procesos. Registro Oficial Suplemento 506 del 22 de mayo de 2015. Artículo 89.

Código Orgánico Administrativo. Registro Oficial Suplemento 31 del 7 de julio de 2017. Artículos 248-250

Código Orgánico de la Función Judicial. Registro Oficial Suplemento 544 del 09 de marzo de 2009. Artículo 108.

Código Orgánico Integral Penal. Registro Oficial Suplemento 180 del 14 de febrero de 2014. Artículo 280.

Constitución de la República del Ecuador. Registro Oficial 449 del 20 de octubre de 2008. Artículo 76.

Convención Interamericana contra la Corrupción. Artículo 5.

Ley Orgánica del Sistema Nacional de Contratación Pública. Registro Oficial Suplemento 395 del 4 de agosto de 2008. Artículos 23-26, 59.

Ley Orgánica de Garantías Jurisdiccionales y Control Constitucional. Registro Oficial Suplemento 52 del 22 de Octubre de 2009. Artículo 42.

\section{Jurisprudencia Constitucional}

Corte Constitucional del Ecuador. Sentencia No. 5-13-IN/19, Caso No. 5-13IN de 2 de julio de 2019. Juez ponente: Ramiro Ávila Santamaría. Gaceta Judicial No. XI del 2019. 
Corte Constitucional del Ecuador. Sentencia No. 3-19-CN/20, Caso No. 3-19-CN de 29 de julio de 2019. Juez ponente: Alí Lozada. Gaceta Judicial No. II del 2020.

\section{Jurisprudencia Interamericana}

Corte Interamericana de Derechos Humanos. Caso Zegarra Marín vs Perú. Emitida el 15 de febrero de 2017.

\section{Jurisprudencia Comparada}

Corte Constitucional de Colombia, Sentencia No. C-417-1993 Gaceta Judicial No XXII de 1993.

\section{Decisiones judiciales}

Corte Nacional de Justicia. Sala de Casación. Sentencia No. 16281-2016-0013

Corte Nacional de Justicia. Sala de Casación. Sentencia No. 256-2013-SF

Corte Nacional de Justicia. Sala de Casación. Sentencia No. 234-2013

Corte Nacional de Justicia. Sala de Casación. Sentencia No. 1772120161704 